\title{
ACUTE TRACHEO-BRONCHITIS
}

BY'

\author{
V. E. NEGUS \\ London
}

(RECEIVED FOR PUBLICATION NOVEMBER 16, 1951)

Considerable attention has been directed to acute tracheo-bronchitis of recent years, and marked improvement has been reported in the treatment of what is a very serious condition. It is desirable to begin by classifying the types of disease, particularly since the treatment varies much according to the causative agent.

An acute reaction readily occurs in the sensitive mucosa of the tracheo-bronchial tract, of columnar ciliated type except in the atria and alveoli, where there are no cilia. The larynx is lined by ciliated epithelium, except over the vocal folds, the covering of which is squamous.

\section{Classification}

Not all cases are due to bacterial infection, many being of an allergic nature, in response to the irritation of proteins, of oils, or of gases. They may be divided as follows: non-specific infection, diphtheria, vegetable foreign bodies, irritating oils and gases.

The pathological factors common to all are swelling of the mucosa, the production of secretions, and sometimes sloughing of the epithelium.

\section{Anatomical Considerations}

Larynx.-A marked feature of many cases is laryngeal obstruction, which is particularly obvious and dangerous in very young children. A study of the larynx of infants explains the reason, when it is realized how small are the diameters of the glottis and trachea and how relatively constricted is the aperture of the larynx in relation to the trachea (Figs. 1 and 2).

Most animals (Fig. 3), and éspecially those of active or fast running habit, have long arytenoid cartilages, long membranous folds, and in many instances a larynx expanded in a funnel-like manner, giving it a cross-sectional area equal to, or greater than, that of the trachea (Negus, 1949). The human species has not these advantages, the larynx being smaller in cross section than the trachea, particularly in infants, there being very considerable growth in older children, with obvious expansion by the age of 5 (Fig. 1).

It is also to be noted that the mucosa of the subglottic region is particularly lax in infants (Jackson and Jackson, 1945) and capable of swelling to a considerable degree ; the squamous epithelium of the vocal folds, on the other hand, is firmly bound down and unlikely to cause obstruction unless sloughing occurs. 


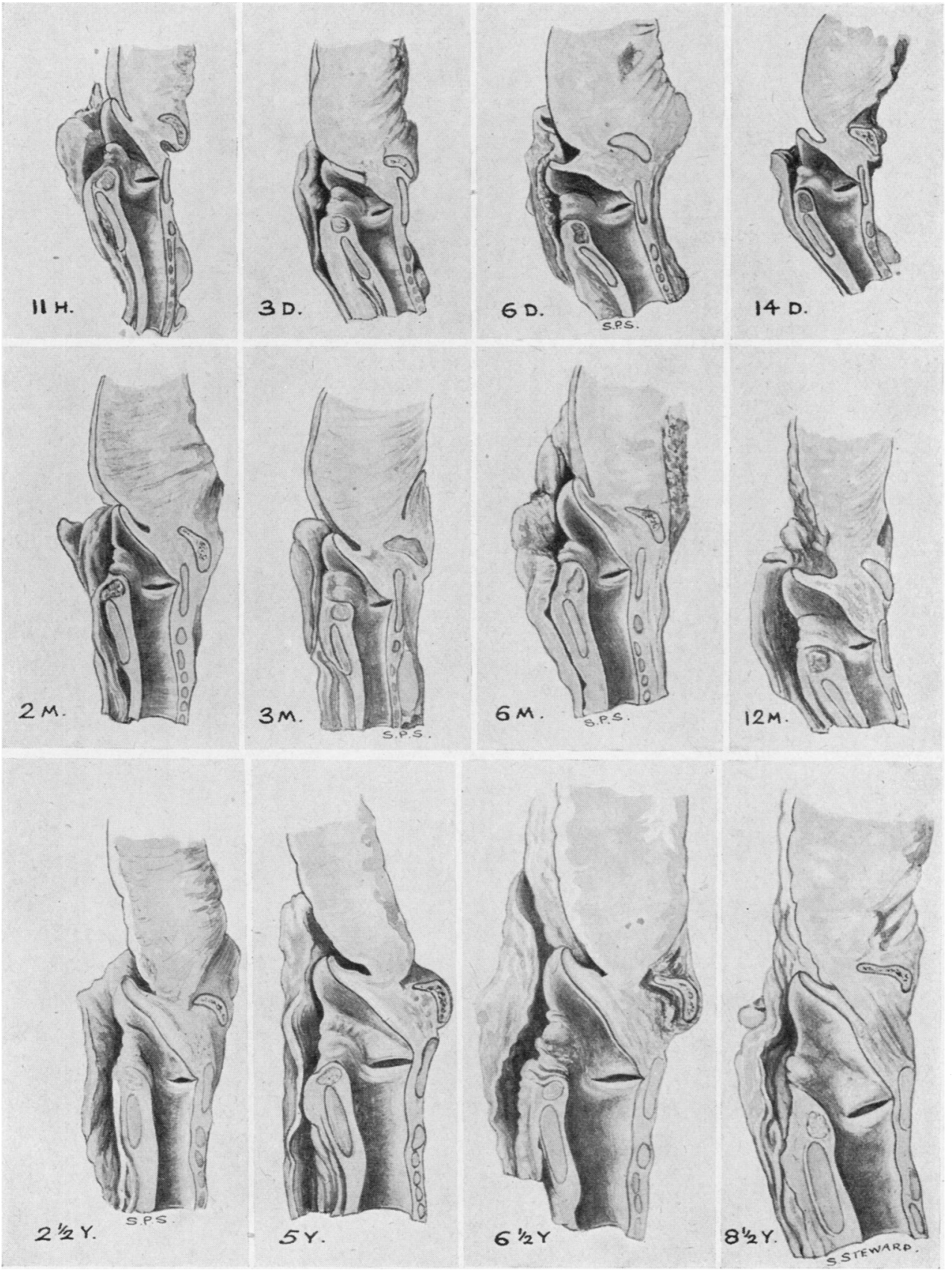

Fig. 1.-The size of the larynx and trachea at different ages. The great difference between the calibre at the ages of $2 \frac{1}{2}$ and 5 years is well shown. 

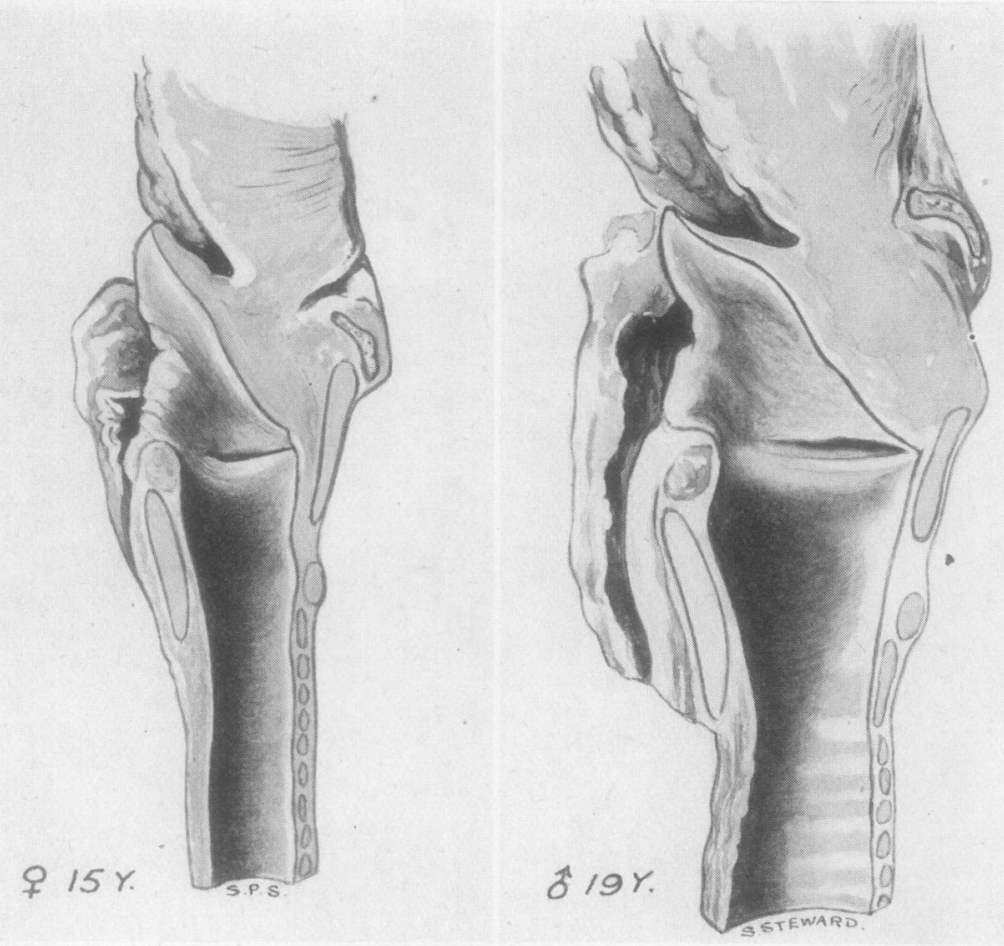

Fig. 2.-The larynx of adults illustrating the considerable enlargement in the male.

All drawings are to the same scale and previously produced in "Comparative Anatomy and Physiology of the Larynx." Negus, 1949. London. Heinemann.
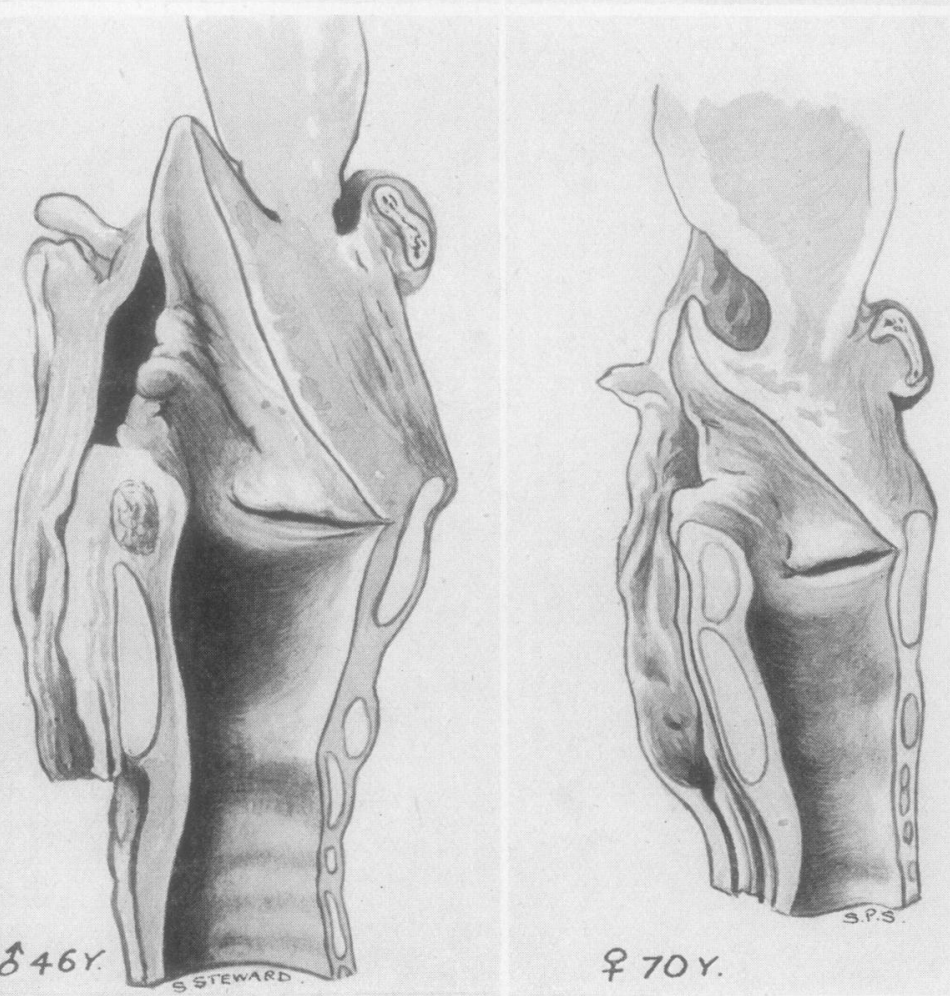


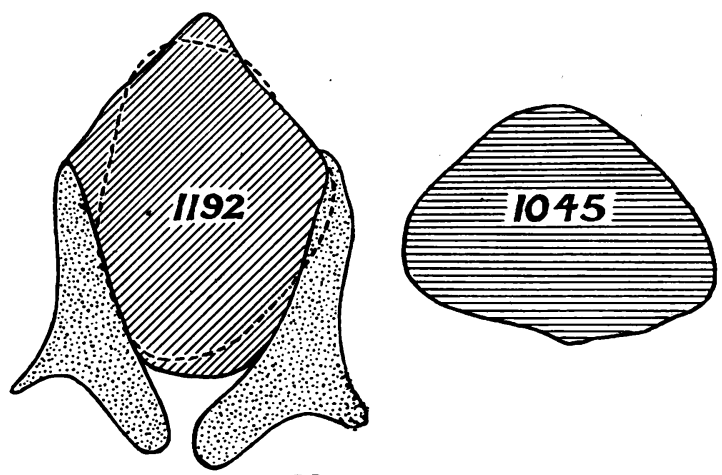

HORSE. II4: 100.
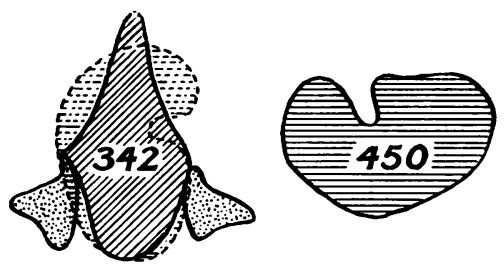

TIGER. 76:100.
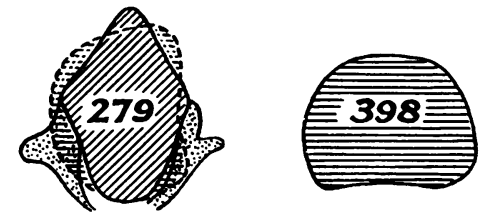

STAGHOUND.70:100.

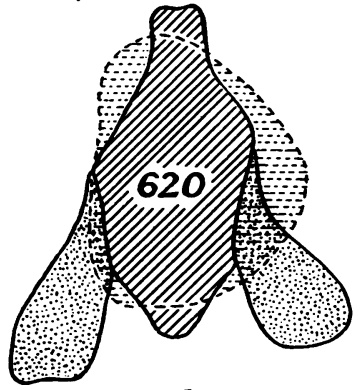

Musk OX. 69: 100.

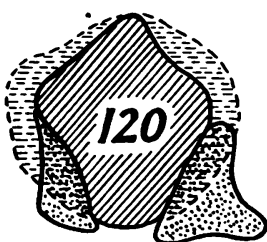

SHEEP. 69:100

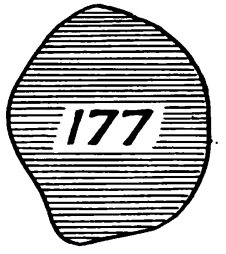

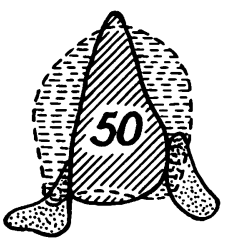

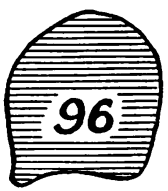

WOMAN. 52:100.

FIG. 3.-Cross-sectional areas of the larynx and trachea in animal and human species. The aperture of the open larynx in the horse is considerably greater in cross-sectional area than the trachea; in the woman the glottis is very much smaller than the trachea. This disproportion is present throughout life in man.

Previously produced in "Mechanism of the Larynx." Negus, 1929. London. Heinemann.

Bronchi.-Hilding $(1948,1949)$ has carried out investigations which show that the trachea, primarily dividing into two main bronchi, is almost equal in crosssectional area to the sum of the terminal bronchioles, which number 25,000 or more. The lumen of each of the finer air passages is extremely small and easily plugged by secretion, which may arrive as droplets. 


\section{Principles of Treatment}

General principles apply, whatever the cause : the first principle is to remove the cause. This calls for the removal of a vegetable foreign body by direct bronchoscopy, for the removal of oils by the same means and stopping the instillation of oily nasal drops if that has led to the tracheo-bronchitis, or for the exclusion or neutralization of irritating gases. Bacterial infection is controlled by the appropriate antibiotics. The second necessity is to relieve laryngeal obstruction. This may be brought about by removing the cause if that can be found, or may follow the reduction of inflammatory swelling caused by bacteria.

Bronchoscopy is necessary in many cases, sometimes to discover and, if possible, to remove a foreign body, and in other cases to aspirate obstructing secretions. When sloughs form in the larynx, a laryngoscope is the instrument employed, particularly in diphtheria. A single procedure may be sufficient to restore the laryngeal airway.

It is highly important, if a bronchoscope is passed, to make certain that it is not too big ; the Suckling bronchoscope, of a diameter of $15 \mathrm{~mm}$., is suitable for infants of a few weeks' and sometimes of a few months' age in a small patient. Too large a tube may cause subglottic swelling and obstruction.

If obstruction persists, tracheostomy must be performed and not too late ; according to Everett (1951), early or not at all. It is essential to make the opening well below the larynx, preferably at the level of the third or fourth ring of the trachea, avoiding the first and second rings ; if these be cut inadvertently the cannula should be replaced at a lower level as soon as tranquil respiration is restored.

The introduction of a bronchoscope or an intubation tube before and during the operation is of great help and is a means of safety. Intubation, as an alternative to tracheostomy, is not recommended.

The third requirement is the removal of secretions. It may be necessary to liquefy these by means of nebulized water delivered from a mechanical humidifier (Jackson and Jackson, 1945 ; Everett, 1951) rather than by steam, which has the fault of condensing. Wetting agents, to reduce the surface tension of water, have been suggested ; potassium iodide is also of use. Humidification of air in the room or ward, up to a relative humidity as high as $70 \%$, may be of help. Aspiration of secretions may be carried out through a bronchoscope, but repeated passage of a rigid tube is not advisable ; the use of a flexible aspirator, passed under guidance through the glottis, is preferable. The presence of a tracheostome is of great assistance for suction (Jackson, 1927) and may, in fact, be performed for this purpose ; a catheter can be introduced by the nurse as often as is necessary.

Fourth, the passage of gases through the alveolar epithelium may be facilitated by moistening the air, by removing obstructing secretions, and by introducing oxygen in helium, which not only allows oxygen to pass in, but also helps to remove $\mathrm{CO}_{2}$. It might be practicable to introduce the gas by means of a tube connected to the tracheal cannula as preferable to a mask, which is not well tolerated by an infant.

\section{Acute Tracheo-Bronchitis Caused by Vegetable Foreign Bodies}

The type of acute tracheo-bronchitis caused by vegetable foreign bodies is the one to which I propose to direct particular attention. The vegetable substances may be fragments of peanut, brazil nut, almond, or walnut, the pips of oranges, lemons, 
or melons, or such substances as carrot, grains of corn, beans, or ginger (Mackenzie, 1880-84).

The symptoms appear rapidly, with pyrexia, dyspnoea, cough, and the expectoration of much frothy sputum ; the condition may be fatal, especially in infants or small children (Clerf, 1924), who may expire in a few hours, probably from subglottic obstruction.

The foreign body descends with the inspiratory air current as far as its size allows ; it then lodges on a spur, allowing air to enter during inspiration, when the bronchi dilate, and preventing its escape during expiration, when they contract (Jackson, 1915, 1927 ; Jackson and Jackson, 1936).

Obstructive emphysema thus appears in a lobe or the whole of a lung; there is hyperresonance and absence of breath sounds. Before becoming impacted the light object may pop up and down in the trachea with the production of asthmatoid wheeze, an audible flop (Brünings, 1912) or palpatory thud (Mackenzie, 1880-84).

Radiographs, which must be taken at full inspiration and full expiration, show increased translucency of the obstructed lung, especially noticeable by contrast during expiration, flattening and limitation of the movement of the diaphragm, and displacement of the mediastinum, which moves towards the obstructed side on inspiration and towards the unobstructed side during expiration.

Complete obstruction of a bronchus leads to atelectasis, due partly to absorption of air by the blood stream, and to its removal by ciliary action (Hilding) associated with accumulation of secretions.

Mucosal Changes.-The sudden appearance of mucosal swelling and the outpouring of secretions are characteristic of an allergic process and quite unlike bacterial inflammation, which is slower in developing and secondary to the primary changes (O’Brien, 1948 ; Criep and Hampsey, 1937).

The condition has been named peanut bronchitis (Jackson, 1915 ; Jackson and Spencer, 1919), arachidic bronchitis (Manges, 1924), and vegetable bronchitis (Jackson and Jackson, 1936). The last name is appropriate, as the reaction is common to a variety of vegetable substances. The reaction varies inversely with the age of the child and directly with the length of sojourn (Jackson, Tucker, and Clerf, 1925).

\section{DiffERENTIAL Diagnosis}

There may be no history of the entrance of a foreign body in small children, but in older subjects sudden choking while eating may indicate the cause of subsequent symptoms.

Acute infective tracheo-bronchitis is associated with a generalized inflammation of the upper respiratory tract, which in foreign body cases is unaffected.

Diphtheria seldom affects the trachea and bronchi in the absence of pharyngeal signs; the presence of sloughs is characteristic.

Oils and gases as a cause are generally recognized by the history and by the absence of the localizing signs in the lungs referred to above.

\section{Treatment}

In confirmed or suspected foreign body cases bronchoscopy is essential ; even if some vegetable substance is present but not seen it may possibly be removed by 
aspiration. Even if no object be discovered, bronchoscopy will still have served a purpose, not only in excluding a possible cause but also in clearing the trachea and bronchi of secretions or sloughs. Tracheostomy is required if severe dyspnoea is caused by subglottic oedema.

\section{REFERENCES}

Brünings, W. (1912). Direct Laryngoscopy, Bronchoscopy ard Oesophagoscopy, trans. and ed. by W. Howarth. London.

Clerf, L. H. (1924). Laryngoscope, St. Louis, 34, 784.

Criep, L. H., and Hampsey, J. W. (1937). J. Allergy, 9, 23.

Everett, A. R. (1951). Laryngoscope, St Louis, 61, 113.

Hilding, A. C. (1944). Anesthesiology, 5, 225. (1948). Ann. Otol., etc., St Louis, 57, 217. (1949). Acta oto-laryng., Stockh., 37, 138.

Jackson, C. (1915). Peroral Endoscopy and Laryngeal Surgery. St Louis. (1927). Bronchoscopy and Esophagoscopy, 2nd ed. Philadelphia and London. and Jackson, C. L. (1936). Diseases of the Air and Food Passages of Foreign-Body Origin. Philadelphia and London. (1945). Diseases of the Nose, Throat, and Ear. Philadelphia and London. and Spencer, W. H. (1919). J. Amer. med. Ass., 73, 672.

Tucker, G., and Clerf, L. (1925). Atlant. med. J., 28, 506.

Mackenzie, M. (1880-84). A Manual of Diseases of the Throat and Nose. London.

Manges, W. F. (1924). Surg. Clin. N. Amer., 4, 54.

O'Brien, E. (1948). Laryngoscope, St Louis, 58, 1013. (With many references.)

Negus, V. E. (1929). The Mechanism of the Larynx. London.

(1949). The Comparative Anatomy and Physiology of the Larynx. London. 